\title{
Significado da morte para médicos frente à situação de terminalidade de pacientes submetidos ao Transplante de Medula Óssea
}

\author{
The significance of death for doctors faced with end-of-life care \\ of patients undergoing bone marrow transplants
}

Manoel Antônio dos Santos ${ }^{1}$

Fernanda Cristina de Oliveira Santos Aoki ${ }^{1}$

Érika Arantes de Oliveira-Cardoso ${ }^{1}$

${ }^{1}$ Departamento de Psicologia, Faculdade de Filosofia, Ciências e Letras de Ribeirão Preto Universidade de São Paulo. Av. Bandeirantes 3900 Monte Alegre. 14.040-901 Ribeirão Preto SP. masantos@ffclrp.usp.br
Abstract This study sought to investigate the significance of death for doctors who work with terminally ill patients in the Bone Marrow Transplant (BMT) context. The research was based on a qualitative, methodological and collective case study approach, and used Dejours' psychodynam$i c s$ of work as a theoretical framework. Five practitioners linked to a Bone Marrow Transplant Unit in a university hospital in São Paulo, Brazil, participated in the research. A semi-structured script was applied which addressed the personal, academic and professional experiences elicited by a terminal situation. Data were organized into two categories: "Work and professional identity: the doctor's battle against death" and "Vocation and medical training: it all beggins at home." The results show that, in the medical and hospital context, death is almost always reduced to technical rationality and this must be avoided at all costs. The significances attributed to death are rooted in the values of contemporary society and subjectively perceived through the physician's life trajectory and academic training, which influence how these professionals experience the dying process of the patients.

Key words Attitude to death, Hospital medical team, Physician-patient relations, Palliative endof-life care, Bone marrow transplant, Grieving
Resumo Este estudo teve como objetivo investigar o significado da morte para médicos que atuam com pacientes em condição crítica no contexto do Transplante de Medula Óssea (TMO). A pesquisa foi fundamentada no enfoque metodológico qualitativo e no estudo de caso coletivo, e utilizou o referencial teórico da psicodinâmica do trabalho. Participaram os cinco médicos vinculados a uma Unidade de TMO de um hospital universitário do interior paulista. Aplicou-se um roteiro semiestruturado, que abordava as vivências pessoais, acadêmicas e profissionais suscitadas pela situação de terminalidade. Os dados foram sistematizados nas categorias: "Trabalho e identidade profissional: a peleja do médico contra a morte" e "Vocação e formação médica: tudo começa em casa". Os resultados mostram que, no âmbito médico-hospitalar, a morte é quase sempre reduzida à racionalidade tecnicista e por isso deve ser combatida a qualquer custo. As significações atribuídas à morte são ancoradas nos valores da sociedade contemporânea e subjetivadas nos percursos e percalços enfrentados pelo médico ao longo de sua história de vida e na formação acadêmica, que influenciam o modo como os profissionais vivenciam o processo do morrer dos pacientes.

Palavras-chave Atitude frente à morte, Corpo clínico hospitalar, Relações médico-paciente, Cuidados paliativos na terminalidade da vida, Transplante de medula óssea, Luto 


\section{Introdução}

Dentre as diversas implicações da terminalidade sobre os cuidados em saúde, o impacto da morte para os médicos ainda é uma questão a ser melhor esclarecida, considerando seus reflexos sobre a prática profissional. No cenário hospitalar, os processos de significação da morte estão impregnados das vivências do morrer, no contexto de uma medicina tradicionalmente curativa, que ainda encontra dificuldades em assimilar a filosofia dos cuidados paliativos assistenciais ${ }^{1}$. Nessa vertente, o presente estudo se propõe a abordar os significados da morte para médicos que atuam em situação de terminalidade e como estes se manifestam no exercício da profissão.

A literatura dedicada a analisar os significados da morte para os profissionais de saúde ainda é esparsa, embora tenha despertado interesse crescente nos últimos anos. Tradicionalmente, a atenção tem se voltado para os pacientes, como o estudo clássico de Kübler-Ross², que destaca os diversos estágios psicológicos que o indivíduo em contato com a terminalidade pode vivenciar.

A dificuldade dos profissionais em lidarem com a morte é uma constatação recorrente nos estudos publicados, o que evidencia que, embora a finitude faça parte do cotidiano hospitalar, ainda é um fenômeno "estranho" aos médicos. Ou seja, a ocorrência da morte para os profissionais não é um fenômeno vivido de forma natural, mas acompanhada de inúmeras dificuldades, que sugerem que o sofrimento resultante do contato rotineiro com situações de terminalidade quase sempre é velado e silenciado.

Ao considerar que a atribuição de significados é um processo ativo de construção mental da realidade, pode-se afirmar que os significados influenciam os modos de agir e reagir às situações ${ }^{3}$. Assim, o modo como uma categoria profissional concebe a morte e o cuidado no processo do morrer interfere na forma de se instituir o tratamento e os tipos de cuidado. Isso acaba influenciando, consequentemente, a maneira como as pessoas percebem a doença e o tratamento, e se aceitam ou não a situação adversa.

O presente estudo focaliza os significados da morte e do morrer, e suas consequências no âmbito da sociedade ocidental, na qual constitui lugar comum o fato de as questões relacionadas à finitude da vida despertarem sentimentos intensos e variados, a maioria deles com conotação negativa, suscitando desconforto emocional. $\mathrm{Na}$ prática médica, percebe-se que os profissionais não estão preparados para lidar com essas situ- ações. Por isso estão sujeitos a experimentarem uma gama de sentimentos reativos, como solidão no exercício profissional, perda do senso de missão, cinismo, desesperança, frustração, bem como risco aumentado de esgotamento e depressão. Esses sentimentos reativos podem ter repercussões negativas no cuidado oferecido ao paciente e à família ${ }^{4,5}$.

A literatura postula que essas reações devemse ao fato de que o médico se torna o ator social no qual se deposita a função de deter a morte ${ }^{6}$. Com o processo de secularização, o poder sobre a morte passou da religião para as mãos da sociedade. A morte começou a ser vista de forma intelectualizada, em um esforço cada vez mais acentuado de afastá-la da realidade humana em um processo de higienização crescente ${ }^{7}$. Se, por um lado, nunca antes as pessoas morreram de forma tão silenciosa e higiênica como na época contemporânea, por outro, nunca se despediram da vida em condições tão propícias à solidão. Talvez a aceleração do processo de interdição da morte esteja associada ao deslocamento do local onde ocorre, pois já não se morre em casa, entre os seus. Assim, no ambiente doméstico não existe mais a emoção e a perturbação da morte. Em geral, o indivíduo morre sozinho, longe de seus familiares, na solidão de um leito hospitalar. O hospital passa a ser o novo cenário privilegiado para a morte e dá um sentido também novo a esse ato ${ }^{6,8-10}$.

Nesse contexto, são necessários estudos que atentem para o impacto do fenômeno do morrer sobre a pessoa do médico. Embora muitas vezes passe despercebido, esse fenômeno é vivido com muito sofrimento e conflito ${ }^{11}$, moldando a relação profissional-paciente ${ }^{8}$. Essa vivência angustiante pode prejudicar o profissional no desenvolvimento de suas atividades diante das necessidades do enfermo, além de afetar sua própria autoestima, acarretando sobrecarga e estresse ocupacional ${ }^{12-18}$.

O Transplante de Medula Óssea (TMO) configura uma clínica de alta complexidade e que exige elevado nível de especialização técnica. Esse procedimento invasivo expõe o paciente a inúmeros riscos, sendo significativa a taxa de morbimortalidade ${ }^{17}$. O profissional também está submetido a estressores crônicos em seu cotidiano, o que resulta em vulnerabilidade a riscos, doenças e agravos físicos, estresse e sofrimento mental, condições que justificam a proposta de novos estudos que focalizem esse universo pelo vértice psicoemocional. Nesse contexto de adversidades, emerge a questão de pesquisa: como os 
profissionais médicos que atuam no TMO significam e vivenciam a morte e o morrer de seus pacientes?

A fundamentação teórica do estudo é a concepção desenvolvida por Dejours ${ }^{19}$ para compreender como os trabalhadores conseguem manter seu equilíbrio psíquico em organizações que, ao explorarem o sofrimento de forma exacerbada, fazem com que a expressão da loucura seja a resposta mais esperada. Apesar de intenso, o sofrimento produzido por essas condições extremas de trabalho é contido por estratégias defensivas ativadas pelos trabalhadores, que impedem que a exposição contínua e constante a essas condições penosas se transforme em patologia ${ }^{20,21}$.

Considerando o exposto, este estudo teve como objetivo investigar o significado da morte para os profissionais médicos que atuam com pacientes em condição crítica no TMO.

\section{Método}

Estudo transversal, descritivo e exploratório, de abordagem qualitativa. A estratégia metodológica utilizada foi o estudo de caso coletivo ${ }^{22}$.

O TMO é um campo de intervenção em saúde que vem se consolidando em todo o mundo nas últimas décadas, por meio da aplicação de conhecimentos adquiridos acerca das célulastronco hematopoéticas. Recentemente, tem emergido como procedimento médico inovador para uma série de doenças onco-hematológicas e autoimunes ${ }^{23}$. Dependendo do tipo de transplante utilizado, o índice de mortalidade é significativo, o que coloca os profissionais médicos em contato direto e permanente com as questões da morte e do morrer ${ }^{24-26}$.

\section{Participantes}

Participaram do estudo todos os médicos docentes e contratados $(\mathrm{N}=5)$, que por ocasião da coleta de dados atuavam na Unidade de TMO (UTMO) de um hospital terciário. Três profissionais eram imunologistas e dois hematologistas. Foram preestabelecidos como critérios de inclusão: ter experiência de, no mínimo, um ano no TMO, estar atuando na Unidade no momento da entrevista e manter contato direto com os pacientes assistidos nesse contexto. Foram critérios de exclusão: não ter vínculo empregatício com a instituição hospitalar (médicos residentes) e não prestar assistência diretamente ao paciente da UTMO.

Na Tabela 1 são apresentados os dados sociodemográficos dos participantes, ano de conclusão do curso de graduação em medicina e carga de trabalho semanal. O tempo de inserção no TMO variou de três a 27 anos.

\section{Instrumentos}

\section{Entrevista em profundidade}

Foi utilizada entrevista aberta, enriquecida com perguntas de aprofundamento. A abordagem dos participantes teve como questão norteadora: "Como os profissionais médicos que atuam nesse contexto (de atendimento a pacientes em situação de terminalidade) significam e vivenciam a morte e o morrer de seus pacientes?". Buscou-se, assim, conhecer a vivência desses profissionais de saúde, supondo que esse conhecimento permite entender o modo como eles significam o próprio trabalho, sua relação com os pacientes que vivenciam uma doença terminal, a morte e a si mesmos.

As entrevistas foram complementadas com perguntas que buscaram inquirir aspectos sobre a formação acadêmica, trajetória profissional, significação da morte ao longo da formação pro-

Tabela 1. Caracterização dos participantes segundo idade, estado civil, número de filhos, religião, ano de graduação e carga de trabalho semanal.

\begin{tabular}{cclclcc}
\hline $\begin{array}{c}\text { Participantes } \\
\text { (nomes fictícios) }\end{array}$ & Idade & $\begin{array}{c}\text { Estado } \\
\text { Civil }\end{array}$ & $\begin{array}{c}\text { Número } \\
\text { de filhos }\end{array}$ & Religião & $\begin{array}{c}\text { Ano da } \\
\text { graduação }\end{array}$ & $\begin{array}{c}\text { Somatória da carga de } \\
\text { trabalho (horas/semana) }\end{array}$ \\
\hline Taís & 34 & Solteira & - & Católica & 1999 & $70 \mathrm{~h} / \mathrm{sem}$ \\
Felipe & 34 & Solteiro & - & Católico & 1999 & $40 \mathrm{~h} / \mathrm{sem}$ \\
João & 38 & Casado & 2 & Não tem & 1996 & $60 \mathrm{~h} / \mathrm{sem}$ \\
Cássia & 50 & Divorciada & 3 & Cristã & 1986 & $55 \mathrm{~h} / \mathrm{sem}$ \\
Paulo & 62 & Casado & 2 & Não tem & 1972 & $40 \mathrm{~h} / \mathrm{sem}$ \\
\hline
\end{tabular}


fissional e pessoal, a visão a respeito dos Cuidados Paliativos, o contato com os pacientes em situação de terminalidade e a vivência do processo do morrer.

De acordo com Minayo $^{27}$, a entrevista constitui-se em um dos procedimentos mais utilizados no trabalho de campo, introduzida como forma de coleta das informações sobre um determinado tema científico. É entendida como uma conversa a dois com propósitos predefinidos.

\section{Diário de campo}

A pesquisadora anotou as expressões e os gestos dos entrevistados em caderneta de campo, bem como outros comportamentos não-verbais que pudessem ser de interesse para a análise das entrevistas.

\section{Procedimento}

\section{Coleta de dados}

A entrevista foi realizada individualmente, em situação face a face, em sala reservada do serviço, com condições de conforto e privacidade. O encontro foi agendado no horário de trabalho dos profissionais, ou em outro, de acordo com a conveniência e a disponibilidade dos participantes. A entrevista foi audiogravada mediante consentimento.

\section{Análise dos dados}

O corpus da pesquisa foi constituído pelo conjunto de entrevistas transcritas na íntegra e literalmente. $\mathrm{O}$ material transcrito foi submetido à análise de conteúdo temática, que seguiu as etapas de pré-análise, descrição analítica e interpretação referencial ${ }^{27}$.

Foram seguidas as normas definidas pelo Conselho Nacional de Saúde, na Resolução no 196/96 sobre pesquisa envolvendo seres humanos $^{28}$. O projeto foi aprovado pelo Comitê de Ética em Pesquisa da instituição hospitalar.

\section{Resultados e Discussão}

A partir da análise temática emergiram as seguintes categorias: "Trabalho e identidade profissional: a peleja do médico contra a morte" e "Vocação e formação médica: tudo começa em casa".
Trabalho e identidade profissional: a peleja do médico contra a morte

A questão da morte abre uma ferida narcísica na prepotência médica. O profissional se vê destituído de sua função precípua, deter a morte, e sente dificuldade de desviar a atenção da cura para a perspectiva dos cuidados paliativos. A morte passa a ser vista como uma temivel adversária ${ }^{16}$. Na guerra imaginária entre vida e morte, o paciente terminal passa a ser o símbolo vivo de uma derrota, o que suscita desconforto naquele que dele se aproxima com o intuito de restituirlhe a condição de saúde.

Esses aspectos que rondam a temática da morte e do morrer não aparecem suspensos no cotidiano do fazer médico, mas inseridos no universo de valores e atitudes aprendidos desde o universo acadêmico, onde ganham força e influência ${ }^{6}$. A formação dos profissionais da saúde, em especial de médicos e enfermeiros, é consistentemente voltada para o modelo biomédico e não contempla os aspectos emocionais ${ }^{29}$. O estudante é preparado para a nobre missão de curar, salvar vidas, anulando a possibilidade de manter uma proximidade humana com a finitude. Há lacunas nos cursos de graduação, que desconsideram que os profissionais da saúde são seres humanos constituídos de dimensões tanto psicológicas quanto físicas.

Para Dejours ${ }^{30}$, a identidade se desenvolve e se completa por meio do trabalho, de maneira que o modo como o indivíduo se apropria e realiza a tarefa imprime significado não só à atividade, como também constrói o ser do trabalhador, tornando o trabalho uma interação dinâmica fundamental ao desenvolvimento, além de ser expressão da vida mental. O trabalho dos médicos na UTMO os expõe à convivência diária com pacientes que estão vivenciando o processo de morrer. Essa proximidade com a finitude humana promove condições e imprime características particulares à organização do trabalho e, consequentemente, segundo a análise da reciprocidade do fator trabalho-identidade proposta por Dejours $^{30}$, evoca aspectos particulares da identidade dos profissionais.

O reconhecimento do "ser médico", peça-chave nessa edificação da identidade, como aponta Dejours $^{30}$, inicia-se no macrocontexto no qual ele está inserido: a sociedade, que por sua vez repercute na formação desses profissionais e no modo como cada um concebe sua história de vida e sua função social. Ao longo do processo histórico, o "ser médico" foi personificado como 
curador, eminente salvador de vidas, provedor de cuidados, pródigo de dons e saberes, em alguns momentos visto como próximo dos místicos e mágicos, detentor de poderes que os colocavam em um patamar acima dos demais seres humanos. Por conseguinte, tal imaginário, atravessado de idealização, privava a figura do médico de características humanas, como suscetibilidade ao cansaço, à dor e ao sofrimento, prevalecendo a visão de um ser imune à falha. Uma das participantes afirma:

... é difícil a gente lidar com a falha do tratamento [...] Apesar de a gente estar numa profissão em que a falha, ela não deve existir, porque a falha pode custar muito caro. (Tais)

O século XX assistiu a um modo de administração da morte no qual a medicina, devido aos seus avanços técnicos, passou a ser a instância responsável tanto pela eficácia e esperança de postergar a morte, como por seu ocultamento social. Assim, a morte é ocultada socialmente por meio de sua delegação ao médico e ao hospital, tornando-se medicalizada, institucionalizada, racionalizada e rotinizada ${ }^{31}$. O médico tornou-se o grande responsável por combater e vencer a morte; é o ser tanatolítico, palavra que tem origem no grego tanatos (morte) e litis (destruição), aludindo, portanto, à pessoa que teria o poder de aniquilar a morte.

Na prática, é o médico quem decide, tecnicamente, o momento da morte e as circunstâncias do morrer. Assim, nas condições do cuidado no final da vida, o profissional pode se assumir onipotente e priorizar salvar o paciente a qualquer custo, a fim de corresponder às expectativas idealizadas de preservador de vidas. Isso o leva a ministrar medidas fúteis com o único objetivo de prolongar a morte anunciada. No entanto, a ocorrência inevitável da morte e a existência das doenças incuráveis derrubam tais preceitos, fazendo o médico se defrontar com sua relativa (in)significância diante de situações irreversíveis. Esse enfrentamento provoca um abalo na dinâmica do reconhecimento de seu trabalho, com impacto sobre o desenvolvimento e a manutenção de sua identidade, uma vez que confronta $o$ que se é e o que se esperava ser. Nesse cenário, a morte pode ser vista como uma derrota, um fracasso $^{29,32}$, pois os membros da equipe veem-se diante de um limite intransponível, que muitas vezes é percebido como uma limitação de sua capacidade profissional ${ }^{33}$.

A morte foi inserida em uma "empresa técnica de produção industrial”, de modo que perdeu sua conotação de experiência humana e, em mui- tos casos, tornou-se "uma sentença dependente do profissional médico" ${ }^{34}$. Essas características da morte e do morrer na sociedade secularizada podem ser identificadas nas falas de Taís, ao apontar as dificuldades de suportar a realidade que o trabalho apresenta, uma vez que o transplante de células-tronco oferece a possibilidade de cura, porém também implica em risco de morte do paciente em decorrência da agressividade do procedimento.

Uma coisa que é difícil da gente lidar é com a falha do tratamento, porque o tratamento pode dar certo, o paciente pode ter sucesso e estabilização da doença, mas ele também pode passar por um tratamento que dá uma pausa na vida dele e de outras pessoas da família durante alguns meses e isso não adiantar nada. Então, essa decepção da falha do tratamento é que, nesse momento, é pior pra gente. (Taís)

... a gente acaba contando mais com a possibilidade da cura mesmo. (Taís)

Mas, muitas vezes, a gente tem falhas no contato com as pessoas, às vezes você não tá num dia bom, você também tem os seus problemas, você não está bem o tempo todo, você também fica doente, você também, né? E... Então, muitas vezes acontecem falhas nesses pontos, você não trata o paciente como você deveria ter tratado, e depois você pára e pensa: 'Nossa, falei aquilo, não deveria ter falado, fui ríspida, né?'

[pesquisadora] Uhum. E como que é encarar essa exigência? Não poder falhar?

É complicado, né? Porque você tem que exigir muito de você, e eu já tenho um perfil muito, assim, de perfeccionismo, de detalhar muito as coisas, eu tenho esse perfil. Então é muito complicado porque você se cobra muito, você se dá demais, se doa demais e você... para você mesmo, você trabalha pouco. (Tais)

O depoimento de Taís evidencia a força da concepção do médico como infalível, pois é o grande responsável pela cura - ou, nos casos em que a cura não é possível, pela morte do paciente. A manutenção dessa crença exige que se afaste ou até mesmo que se denegue - a possibilidade de morte, uma vez que esta é vista como falha, causando intenso sofrimento justamente pela incongruência percebida entre aquilo que, idealmente, o profissional deveria ser com aquilo que ele realmente pode ser. Dessa forma, no meio médico não se pode pensar em morte, pois ela não é vista como um desenlace possível ${ }^{6}$ ou como boa companheira.

O depoimento de Felipe também mostra essa tentativa de afastamento da realidade incômoda 
da morte ao justificar que sua escolha pelo serviço se deu justamente pela possibilidade de promover a cura em casos extremamente graves e refratários às terapêuticas convencionais. Esse participante conta que, em sua experiência anterior de trabalho na hematologia, presenciou muitas mortes: $O$ que me estimulou muito [no TMO] foi exatamente pela perspectiva de cura.

Também na fala de Paulo pôde-se perceber nitidamente a concepção dominante da morte como resultado de uma "falha terapêutica", que "expõe uma fragilidade do conhecimento médico":

É, é muito difícil, porque se você fica... você fica frente a uma falha terapêutica, se o paciente morre, você não conseguiu curá-lo, então de certo modo é uma falha, não sua, mas da medicina, né? Então isso expõe uma fragilidade do conhecimento médico, e você se envolve muito com o paciente que vai morrer, com a família, né? É, é uma situação muito difícil. (Paulo)

A fala de Paulo mostra como o próprio trabalho no TMO é concebido, por esse participante, como uma missão salvacionista. A morte como desfecho oposto ao esperado (a cura).

Em relação à morte dos pacientes, como eu trabalho em uma área de ponta na medicina, que éo transplante... que se propõe a curar todos os pacientes que são transplantados, nosso propósito é o de curar, não é um tratamento paliativo, é de curar... Quando um paciente morre é que o procedimento falhou. Então, é uma falha não pessoal, não sinto que é uma falha minha, ou de algum membro da equipe... (Paulo)

Ainda que a morte seja uma possibilidade de desfecho do tratamento, é vista como alheia ao mesmo, podendo causar sentimentos de culpa e frustração nos profissionais que se deparam com essa possibilidade.

[...] Às vezes tem alguma falha, isso é pior, às vezes alguém morre por uma falha de alguém da equipe, então isso cria um problema enorme, que além do problema da morte, que já é difícil, tem o problema da culpa, de apurar a responsabilidade. A pessoa se sente culpada, chega a um, você imagina o problema que dá, né? Mas a morte do paciente no contexto do transplante indica que o procedimento falhou. Aquilo que a gente queria, que era curar o paciente, nós não conseguimos. É uma fatha, e isso dá uma frustração. (Paulo)

Assim, é preciso que o acompanhamento do processo do morrer seja afastado da função médica, o que é explicitado no excerto de fala a seguir:

Era muito difícil, era o mais difícil, de ter que enfrentar essa situação da perda, né? A perda é sempre complicada. Então a gente... Quando você faz medicina, você faz pra pessoa viver, não pra ajudar a morrer... Então era pior, né? Lidar com a morte é pior. (Taís)

\section{Vocação e formação médica: tudo começa em casa}

Já no início da formação médica, o acadêmico de medicina tem seu primeiro encontro com a morte durante as aulas de anatomia. Nelas o aluno é apresentado à morte na condição de um corpo desvitalizado e desmembrado em peças ${ }^{35}$, fragmentado e destituído de sua identidade, sequestrado de sua história. Seu primeiro contato com a morte é feito de maneira despersonalizada, começando ali muitas vezes um processo de expropriação dos sentimentos e de denegação dos aspectos existenciais e simbólicos da morte e do morrer $^{36}$. Essa iniciação brutal funciona como uma espécie de batismo de fogo, causando grande impacto nas maneiras como o futuro profissional conceberá a morte em seu trabalho.

As falas dos participantes evidenciam a vivência desse contato impactante com a morte no primeiro ano de graduação:

Eu lembro que, no início, eu fiquei muito chocada, porque uma das primeiras matérias em medicina é anatomia, aí você já entra e já vê aquele monte de cadáver em cima da mesa... E você acha que você entrou na faculdade para cuidar de gente e não de defunto... Então foi um choque muito grande o começo da faculdade, com todos aqueles defuntos deitados ali na mesa... E é interessante que foi nesse dia, eu lembro como se fosse hoje, eu tava lá com todos aqueles defuntos. Ali que eu imaginei que devia ter alguma coisa além do corpo, né? Porque ali você só via aquele corpo, né? Então eu pensei: 'Deve ter alguma coisa além, que faz aquele corpo ser alguém, que ali você só via aqueles pedaços de corpo, aquelas peças... Então isso foi muito traumático para mim no começo da faculdade. E aí, quando você começa, fica muito difícil você entender o sentido daquilo'. (Cássia)

Mas, uma coisa que foi muito difícil pra mim, foi quando a gente tinha sido obrigado a assistir necropsia. Então as necropsias eram muito complicadas para mim, ver aquela situação. Nisso eu tive um pouco de dificuldade sim. Eu acho que era o nosso contato, o primeiro contato mesmo com a morte. Eu acho que isso foi mais complicado. Então, quando a gente fazia patologia, eu acho que no terceiro ano, a gente era obrigado a assistir a dez necropsias. (Taís)

E esse contato com a morte, no primeiro momento, é muito chocante, a gente não tem um pre- 
paro pra isso. E é certo que é um contato diferente do que a gente tem hoje, né? Porque depois, quando você tem o contato mesmo com o paciente e esse paciente morre, a situação é diferente porque você teve um contato pessoal e depois aquela pessoa morreu. Na necropsia não, você já encontrava a pessoa morta, então você não tinha... um contato, uma ligação. Mesmo assim, foi muito complicado pra mim nesse momento. (Taís)

Esses segmentos de fala evidenciam a falta de preparo para o encontro e o trabalho com a intimidade da morte. A morte é apresentada ao estudante de medicina por um viés reducionista. É simplesmente a perda das funções vitais e não da subjetividade, dos sonhos, dos desejos e dos projetos que animavam aquele corpo inerme que um dia pertencera a alguém. A morte, quando faz sua aparição no contexto da formação médica, é apenas em seu sentido biológico, anatômico, desprovido de simbolismo. O profissional que está sendo preparado na academia é colocado no lugar de executor de uma tarefa mecânica, sem ter um continente psíquico para poder abrigar as angústias e sentimentos suscitados pelo encontro cru e concreto com a dimensão da finitude.

Os cursos de medicina não preparam o aluno para enfrentar situações que envolvam a morte e o processo de morrer ${ }^{37,38}$. Na verdade o que fazem é prepará-lo para lidar com essa problemática por meio do uso de mecanismos de defesa, como a negação, a evitação e a racionalização ${ }^{8}$. Quando os estudantes entram em contato com pacientes que estão vivenciando a situação de terminalidade geralmente experimentam ansiedade, angústia e medo. Frequentemente referem que não sabem lidar com a situação. É interessante destacar que os estudos indicam que, embora o aluno muitas vezes tenha o conhecimento sobre as características e os procedimentos dos cuidados no fim de vida, esse saber não é necessariamente atrelado à percepção de ter adquirido competência para lidar com as situações terminais ${ }^{38}$. Outras pesquisas mostram ainda que, embora os residentes dominem o conhecimento de cuidados paliativos e saibam conversar sobre as questões da terminalidade, acreditam não fornecer apoio emocional aos pacientes e não se sentem suficientemente aparelhados para realizar essa tarefa ${ }^{14,37,39}$.

O depoimento de outra participante, Cássia, apresentado anteriormente, demonstra a tentativa de integração da experiência psíquica fragmentada nas aulas de anatomia, concretizadas nas "partes de um cadáver" e na morte despersonalizada, buscando um sentido para o humano e para a morte.
Um sentido que possa ser integrador das experiências parciais: deve ter alguma coisa além que faz aquele corpo ser alguém, que ali você só via aqueles pedaços de corpo, aquelas peças. Nota-se, assim, o esforço da profissional para transcender a realidade concreta dos corpos inertes sobre a superfície fria da mesa de mármore e ir além da morte factual, personalizando-a. Só assim seria possível se apropriar da experiência, dar-lhe um sentido totalizante, integrando o que poderá ocorrer no futuro com o paciente moribundo. Sem deixar de expor o quão traumática foi essa experiência de dissociação da morte e do ser humano finito.

Dejours $^{30}$ aponta que, frente a situações desestabilizadoras de extremo sofrimento, as pessoas tendem a mobilizar mecanismos que mantenham o equilíbrio psíquico, seja por meio de mecanismos de defesa como a negação, a dissociação entre os fatos e os sentimentos provocados por eles, a racionalização, entre outras defesas psíquicas, ou por meio da tentativa de sublimação, como fez Cássia, que frente à descompensação gerada pelo sofrimento buscou uma integração da experiência. Essa integração foi buscada, em primeiro lugar, ao se perceber emocionalmente afetada pela situação a que estava exposta; depois, por meio de uma operação reflexiva, na qual a então estudante se indagou o sentido transcendente que poderia estar subjacente ao sofrimento vivido. Nesse momento, Cássia pôde nomear o que se passava em sua intimidade psíquica, que é uma condição para a simbolização da experiência. Doravante, o ganho psíquico resultante dessa elaboração permitirá que experiências semelhantes sejam enfrentadas e manejadas com menor sofrimento.

As falas dos participantes convergem ao apontarem para o despreparo da formação acadêmica frente a situações extremas que colocam o profissional diante de situações liminares entre vida e morte.

Então, o que me desagradava eram algumas disciplinas que tinham essa característica desse distanciamento. (Felipe)

Em termos de deficiência, eu acho que é basicamente essa questão... o corpo docente ainda não tava bem treinado para essa mudança que vem ocorrendo ao longo desses anos, de vocêformar pessoas que tenham uma habilidade maior para resolver problemas. Eu acho que esse é o diferencial do ensino baseado em problemas... a questão de como lidar de uma forma saudável com os conflitos do trabalho... (João)

Além das limitações da formação acadêmica e do imaginário social, a história de vida de cada 
um também é fator essencial na formação da identidade do profissional e no modo como este vai conceber o trabalho e a si próprio no exercício de tal atividade, pois cada experiência imprime diferentes modos de reconhecimento de si, podendo influenciar os reconhecimentos que serão buscados na atuação profissional. Assim, o modo como a figura do médico era delineada no imaginário de cada um, o lugar que a morte ocupava no imaginário da família e as experiências de aproximação à finitude ao longo da trajetória pessoal parecem ser os eixos balizadores das vivências e significados particulares atribuídos por cada um frente a um trabalho aparentemente semelhante.

Taís relata que buscou a medicina por dois motivos: a vontade do pai em ter um filho médico e a vontade de ajudar, e quanto à presença da morte em sua história de vida, conta que sempre teve uma conotação religiosa, havendo pouco espaço disponível para a conversação sobre esse tema no contexto familiar:

...E, eu tinha uma personalidade, de querer fazer tudo certinho, de querer ser motivo de orgulho. E aí eu ouvia isso [a vontade do pai] e eu coloquei na minha cabeça que eu ia ser médica. Quando a gente é criança, a gente acha bonito, né? aquela coisa de ajudar. Todo mundo que escolhe fazer medicina, principalmente na idade em que eu escolhi, na infância, não pensa em ganhos financeiros, que hoje é muito difícil diante dessa profissão, mas principalmente nisso, numa realização pessoal, no ajudar o outro. (Taís)

Eu vivenciei a perda de muita gente, de muitas pessoas queridas desde quando eu era muito pequena. A gente não conversava assim... sobre morte, porque isso era uma coisa... que tem uma pauta familiar religiosa, então a minha formação é católica e quando alguém morria: 'Ah, essa pessoa foi pro céu', né? E até hoje eu encaro dessa maneira. Então, se essa pessoa faleceu, Deus quis dessa maneira, Deus quer essa pessoa perto Dele, eu ainda tenho esse tipo de pensamento. (Taís)

O reconhecimento não é uma revindicação secundária no trabalho, mas um elemento decisivo para manter a motivação do trabalhador ${ }^{31}$. Pode-se pensar que essa identificação de Taís ao reconhecimento buscado pelo pai, por meio da profissão médica, pode ter sido a primeira mola propulsora da escolha profissional da filha e até mesmo pode ter se transferido para suas demais buscas por valorização ao longo da carreira. Podese perceber que, para essa participante, o falar abertamente sobre a morte não é visto com naturalidade ou como parte do exercício de sua profissão, assim como aprendera em sua infância.
Felipe relata que em sua casa se conversava sobre a morte, porém superficialmente, e que ele não passou por nenhuma perda significativa em sua infância.

Eu acho que sim, mas nada assim com profundidade, não. A gente conversava. Acho que sim, algumas vezes sim. Mas nada com profundidade. (Felipe)

João conta que veio de uma família de médicos e que o modo de seus familiares entenderem a medicina como ajuda ao outro sempre o marcou muito, assim como a naturalidade com que a morte irrompia nas conversas familiares. Admite que se podia falar até mesmo da própria morte, o que ele julga que o auxiliou no modo de compreender o fim da vida e a importância de se aproximar da morte, conversando e acompanhando de perto os pacientes terminais.

E, lógico, a vontade de ajudar sempre, dentro da minha casa a medicina nunca foi vista como um comércio, os dois tinham uma visão muito humana e até posso dizer um pouco romântica da medicina, e isto acabou me influenciando bastante. (João)

O chamado da vocação médica veio de casa. Vocação deriva do latim vocare, que significa chamamento, ato de chamar. Equivale àquela voz interior, que emanaria da alma e que diz o que o indivíduo deve fazer para se autorealizar, ajudando-o a tomar a decisão mais acertada e a seguir o caminho profissional que faz com que ele sinta prazer em realizar determinadas tarefas, que assim se tornam fáceis, por mais árduas que sejam.

Como eu te falei, eu venho de uma família de médicos, tanto meu avô como meu pai. Esse assunto da morte na minha casa nunca foi um tabu, a gente sempre discutiu isso de uma forma muito aberta. Não sem emoção, eu me emociono muitas vezes diante das perdas. Não quero dizer que sou um individuo completamente resolvido diante dessas questões não. Mas eu acho que nunca houve um tabu para discutir essa questão da finitude. (João)

... E hoje eu acredito que, se o paciente der abertura para falar sobre a morte, a gente não pode perder a oportunidade. Por fazer bem, na minha opinião, para o médico e o paciente sempre falarem sobre a possibilidade da morte. (João)

Em contraposição, Paulo relata que, em seu contexto familiar, o tema da morte nunca foi discutido: Não. Não se falava nada disso. Refere ter vivenciado uma perda marcante na juventude, de um irmão que se suicidou aos 25 anos. Afirma que, até hoje, o mais difícil de aceitar em sua profissão é a perda de alguém jovem. 
Para Cássia foi marcante a história de aceitação da finitude por parte do avô, contada pela mãe como uma experiência humana admirável, acrescida da vivência de outras perdas - de uma tia, de uma amiga na infância, em acidente de carro, e de outra amiga, de leucemia, aos 18 anos. No contato com essas experiências ela aprendeu sobre a possibilidade de se aproximar da morte como oportunidade para desenvolver recursos para obter fortalecimento, esperança e equilíbrio $^{40}$. Nessa vertente, conta da amizade que manteve com um professor durante a faculdade. Ele estava morrendo de câncer e passou os últimos dias de sua vida encontrando-se com ela diariamente. Cássia julga que esse foi seu maior aprendizado sobre a vida, a morte e a medicina. Essa relação mestre-discípulo lembra muito o contexto retratado no livro A última grande lição: O sentido da vida, no qual o jornalista Mitch Albom narra sua experiência de ter acompanhado regularmente os últimos dias de vida de seu ex-professor.

Ele sabia do que se tratava, mas ele não queria fazer quimio. Eu, infelizmente, não gravei, mas eu fiquei os três últimos meses da vida dele tomando café com ele. E ele me contou da vida dele e tal... E eu percebi o quanto uma pessoa que está à beira da morte, e sabe que vai morrer, tem para falar e não tem ninguém para ouvir. Todo mundo fala: 'Você vai ficar bom...' Ele sabe que não vai ficar bom. E ele simplesmente quer falar... (Cássia)

\section{Considerações finais}

Este estudo focalizou os médicos e suas vivências do processo do morrer no cenário do TMO. Os participantes discorreram sobre como ocorreu a formação acadêmica no que concerne às questões referentes à finitude, quais as dificuldades enfrentadas no âmbito profissional e pessoal frente à terminalidade e como desenvolvem a relação com o paciente com enfermidade potencialmente fatal.

As categorias temáticas permitiram apreciar algumas das facetas das vivências dos médicos de acompanhar o morrer e a morte como parte do exercício de seu ofício. Ao significar essas vivências, é possível apreendê-lo também em sua dimensão humana, passível de conflitos e ambiguidades que geram sofrimento psíquico a partir do trabalho. Os conflitos tendem a ser escamoteados no cotidiano da prática médica, de modo que o sofrimento resultante passa muitas vezes despercebido e, consequentemente, não se torna objeto de reflexão e cuidado.

\section{Colaboradores}

MA Santos foi responsável pela concepção e orientação do projeto de pesquisa, delineamento metodológico do estudo, análise e interpretação dos dados, elaboração da redação final e aprovação da versão final do artigo. FCOS Aoki foi responsável pela condução do projeto, coleta, análise e interpretação dos dados. EA OliveiraCardoso foi responsável pela supervisão da coleta de dados e revisão da versão final do texto.

\section{Agradecimentos}

Estudo financiado pela Fundação de Amparo à Pesquisa do Estado de São Paulo (Fapesp), e Conselho Nacional de Desenvolvimento Científico e Tecnológico (CNPq), Bolsa de Produtividade em Pesquisa.

\section{Referências}

1. Boemer MR. Sobre cuidados paliativos. Rev Esc Enferm USP 2009; 43(3):500-501.

2. Kübler-Ross E. Sobre a morte e o morrer: o que os doentes terminais têm para ensinar a médicos, enfermeiras, religiosos e a seus próprios parentes. $5^{\mathrm{a}}$ Edição. São Paulo: Martins Fontes; 2005.

3. Pereira MA. Má noticia em saúde: um olhar sobre as representações dos profissionais de saúde e cidadãos. Texto Contexto Enferm 2005; 14(1):33-37.

4. Mascia AR, Silva FB, Lucchese AC, De Marco MA, Martins MC, Martins LA. Atitudes frente a aspectos relevantes da prática médica: estudo transversal randomizado com alunos de segundo e sexto anos. Rev Bras Educ Med 2009; 33(1):40-48.

5. Rezende VL. Os últimos momentos: abordagem psicológica para pacientes terminais. Campinas, SP: Editora da Unicamp; 2000.

6. Azeredo NSG, Rocha CFC, Antonacci PS. O enfrentamento da morte e do morrer na formação de acadêmicos de Medicina. Rev Bras Educ Med 2011; 35(1):37-43.

7. Foucault M. Microfísica do poder. 26a Edição. São Paulo: Graal; 2008. 
8. Moreira SN, Silva CA, Tertulino FF, Tertulino FM, Vilar MJ, Azevedo GD. Processo de significação de estudantes do curso de medicina diante da escolha profissional e das experiências vividas no cotidiano acadêmico. Rev Bras Educ Med 2006; 30(2):14-19.

9. Callanan M, Kelley P. Final gifts: Understanding the special awareness, needs, and communications of the dying. New York: Bantam Books; 1992.

10. Pessini L. Bioética e cuidado do bem-estar humano: ética, humanização e vocação como desafio para os profissionais de saúde [on line]. Rev Bioética 2005 [acessado 2013 mar 14] Disponível em: http:/ /www.redadultosmayores.com.ar/buscador/files/ BIOET004.pdf

11. Boemer MR. A morte e o morrer. 3a Edição. Ribeirão Preto: Holos; 1998.

12. Hanna SA, Marta GN, Santos FS. O médico frente a novidades no tratamento do câncer: quando parar? Rev Ass Med Bras 2011; 57(5):588-593.

13. Leite MA, Vila VSC. Dificuldades vivenciadas pela equipe multiprofissional na unidade de terapia intensiva. Rev Lat-Am Enfermagem 2005; 13(2):145-150.

14. Rhodes-Kropf J, Meier D, Adelman R. Interns learning to care for dying patients. J Palliat Med 2003; 6(6):865-872.

15. Silva GSN, Ayres JRCM. O encontro com a morte: à procura do mestre Quíron na formação médica. Rev Bras Educ Med 2010; 34(4):487-496.

16. Quintana AM, Kegler PS, Maúcha S, Lima LD. Sentimentos e percepções da equipe de saúde frente ao paciente terminal. Paidéia 2006; 16(35):415-425.

17. Oliveira EA, Santos MA, Mastropietro AP. Apoio psicológico na terminalidade: ensinamentos para a vida. Psicol Estud 2010; 15(2):235-244.

18. Costa JC, Lima RAGL. Luto da equipe: revelações dos profissionais de enfermagem sobre o cuidado à criança/adolescente no processo de morte e morrer. Rev Lat-Am Enfermagem 2005; 13(2):151-157.

19. Dejours C. Uma nova visão do sofrimento do sofrimento humano nas organizações. In: Chanlat JF, organizadores. O indivíduo na organização: dimensões esquecidas. 3a Edição. São Paulo: Atlas; 1996. p. 149-174.

20. Dejours C, Abdoucheli E. Psicodinâmica do trabalho: contribuições da Escola Dejouriana à análise da relação prazer, sofrimento e trabalho. In: Betiol MIS, organizador. Itinerário teórico em psicopatologia do trabalho. São Paulo: Atlas; 1994. p. 119-145.

21. Machado AG, Merlo ARC. Cuidadores, seus amores e suas dores: o prazer e o sofrimento psíquico dos auxiliares e técnicos de enfermagem de um hospital cardiológico. Psicol Soc 2006; 20(3):444-452.

22. Stake RE. Case studies. In: Denzin NK, Lincoln YS, editors. Handbook of qualitative research. London: Sage; 2000. p. 435-454.

23. Voltarelli JC, Moraes DA, Ribeiro A, Oliveira MCB, Rodrigues M, Brum DG, Barreira AA, Hamerschlak N. Consenso brasileiro para transplante de célulastronco hematopoéticas para tratamento de doenças auto-imunes. Rev Bras Hematol Hemoter 2010; 32(1):125-135

24. Guimarães FAB, Oliveira-Cardoso EAO, Mastropietro AP, Voltarelli JC, Santos MA. Impact of autologous hematopoeitic stem cell transplantation on the quality of life of patients with multiple sclerosis. Arq Neuro-Psiquiatr 2010; 68(4):522-527.
25. Mastropietro AP, Oliveira EA, Santos MA. Terapia Ocupacional. In: Machado LN, Camandoni VO, Leal KPH, Moscatello EL, organizadores. Transplante de medula óssea: abordagem multidisplinar. São Paulo: Lemar; 2009. p. 337-346.

26. Oliveira-Cardoso EA, Santos MA, Mastropietro AP, Voltarelli JC. Qualidade de vida de sobreviventes do transplante de medula óssea (TMO): um estudo prospectivo. Psic Teor e Pesq 2009; 25(4):529-536.

27. Minayo MCS. $O$ desafio do conhecimento: pesquisa qualitativa em saúde. 12a Edição. São Paulo: Hucitec; 2010

28. Brasil. Ministério da Saúde (MS). Conselho Nacional de Saúde. Resolução no 196 de 10 de outubro de 1996. Diretrizes e Normas Regulamentadoras de Pesquisas Envolvendo Seres Humanos. Diário Oficial da União 1996; 16 out.

29. Ramalho MAN, Nogueira-Martins MCF. Vivências de profissionais de saúde da área de oncologia pediátrica. Psicol Estud (Maringá) 2007; 12(1):123-132.

30. Dejours C. Subjetividade, trabalho e ação. Rev Produção 2004; 14(3):27-34.

31. Menezes RA. Difíceis decisões: Uma abordagem antropológica da prática médica em CTI. Physis 2000; 10(2):27-49.

32. Junqueira LCU. Vivências de médicos oncologistas: um estudo da religiosidade no cuidado existencial em saúde [dissertação]. Ribeirão Preto: Universidade de São Paulo; 2008.

33. Sousa DM, Soares EO, Costa KMS, Pacífico ALC, Parente ACM. A vivência da enfermeira no processo de morte e morrer dos pacientes oncológicos. Texto Contexto Enferm 2009; 18(1):41-47.

34. Falcão EB, Mendonça SB. Formação médica, ciência e atendimento ao paciente que morre: uma herança em questão. Rev Bras Educ Med 2009; 33(3):364373.

35. Vianna A, Piccelli H. O estudante, o médico e o profissional de medicina perante a morte e o paciente terminal. Rev Ass Med Bras 1998; 44(1):21-27.

36. Zaidhaft S. Morte e formação médica. 2a Edição. Rio de Janeiro: Francisco Alves; 1990.

37. Buss MK, Alexander GC, Switzer GE, Arnold RM. Assessing competence of residents to discuss endof-life issues. J Palliat Med 2005; 8(2):363-371.

38. Mulder SF, Bleijenberg G, Verhagen SC, Stuyt PM, Schijven MP, Tack CJ. Improved competence after a palliative care course for internal medicine residents. J Palliat Med 2009; 23(4):360-368.

39. Combinato DS, Queiroz MS. Um estudo sobre a morte: uma análise a partir do método explicativo de Vigotski. Cien Saude Colet 2011; 16(9):3893-3900.

40. Teixeira JJV, Lefèvre F. Significado da intervenção médica e da fé religiosa para o paciente idoso com câncer. Cien Saude Colet 2008; 13(4):1247-1256.

Artigo apresentado em 30/04/2013

Aprovado em 22/05/2013

Versão final apresentada em 22/05/2013 